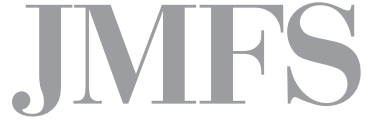

Journal of Management and Financial Sciences
Volume XII

Issue 37 (June 2019)

pp. 75-97

Warsaw School of Economics

Collegium of Management and Finance

\title{
People investing in people. The overview on investment methods in technological start-ups at different stages of growth
}

\begin{abstract}
The purpose of this paper is to explore different funding sources for young technology-based companies at different stages of their development, taking into consideration their characteristics. The study uses data from an extensive literature review on the start-up literature and a desk research analysis. The first part of the article focuses on the explanation of the concept of start-up with an emphasis on internal and external risks it can bear for a potential investor. The middle part of the article offers an overview on various division concepts into phases of a start-up. The final part explains characteristics of different kinds of investors in order to match them with specific phases of growth. The author's findings reveal that the new technology-based firms demonstrate different financing patterns at different stages of development. The article may serve as an interesting overview for start-ups planning their development path as it attempts to reconcile different points of view. However, being based only on existing literature sources, further research is necessary for more profound conclusions.
\end{abstract}

Keywords: start-up, founder, technology-based firm, investment sources, financing sources JEL Classification Codes: G11, M13 


\section{Introduction}

For over a decade now, the term 'start-up' has been functioning as a catchy buzzword thrilling and bringing together entrepreneurs and all sorts of investors. Technological opportunities, globalisation and rapid market expansions created a whole new macro-environment and provided unprecedented business opportunities [Kirley, 2016]. The phenomenon of fast growing technological ventures has inspired non-obvious investing agents, who, for various reasons, including the famous, so-called FOMO (Fear Of Missing Out) were extremely eager to join the trend. Stories of unicorns (technological companies of valuation measured in billions) [Lee, 2013] have even further strengthened this desire for such seemingly quick-wins. On the entrepreneurial side, the rise of technology enabled the vertical economic progress [Thiel and Masters, 2014], meaning accelerating the process of scaling up young companies and enhancing their competitiveness [McNally, 1995]. This has led to an increased interest in the field and the supply of independently created bottom-up ventures in need of external financial support.

The good fame of nascent new technology-based companies stems from the success of well-known giants that have drowned out hundreds of thousands of failed companies that have not survived through the seed stage. The odds are not in favour of the overly-optimistic founders, as various researches show that between five to nine out of ten young companies will most certainly never grow out of the seed stage, meaning reaching up to one million in revenue [www.startupfinancialmodel.com, 2018] and only about 25\% will survive while performing beneath that level. The excitement seems even more astonishing, as start-ups in each of their definitions have a heavy emphasis on the risk undertaken by all involved parties.

\section{Definition of a start-up}

"On day one a start-up is a faith-based initiative built on guesses" [Blank and Dorf, 2012, p. 8]

Start-up's definitions spread from being called 'an acutely human enterprise' [Ries, 2011] to being described as series of hypotheses that are yet to be tested by future customers [Blank and Dorf, 2012]. The authors of the above-mentioned descriptions are world-known entrepreneurial gurus, who have spent years observing the ecosystem from the very epicentre of the whole trend - the Californian Silicon Valley. Theirs, and many others', experience very much entitles them to sum up the potential average outcome in such a harshly honest way. Nonetheless, it is not the idea of the start-up that is being brutally evaluated, but rather a lack of preparation to handle such a concept that causes the general judgement to imply its volatility.

A start-up is not just a smaller version of a regular company [Blank and Dorf, 2012]. It massively differs in terms of procedures and approach to the product development. Young tech ventures of such type are focused on agile engineering that aims at customer-centric output. 
In most situations, the idea for a product comes from existing social, economic or medical issues rather than from the founder's rigid vision [Atherton, 2010]. Entrepreneurs undergo constant a verification process when being confronted with the market: fluctuating trends and restless competition. In those extremely uncertain conditions, one is supposed to find a scalable, repeatable and profitable business model [Blank and Dorf, 2012] that will allow it to reach the phase of commercialization and become an operating business [Blazenko et al., 2012].

Performing such a process of introducing a tech novelty that millions of users eagerly adopt is in fact very challenging, as there is little certainty whether a particular idea or device will be greeted with enthusiasm. Research confirms that a wrong diagnosis of the customer's needs is one of the main reasons for failure, however, according to the disruption theory, if anybody, then start-ups are the most efficient in developing innovations. For this reason, they are so strongly taken into consideration as investment projects [Christensen and Raynor, 2003]. It is despite the fact that the public is aware of information asymmetry that makes them biased because they get to hear only about 'the happy few' successful ventures and are never reached by information on failures, unless one stumbles upon a particular bankruptcy case that the media viciously dwell on. What is more, the industry has become hyper competitive, i.e. it is promoting very short product cycles, while providing very unstable conditions for both existing companies and newcomers. More value-added is expected from each market participant willing to float above the waterline [D’Aveni and Gunther, 1994].

On the other hand, technological start-ups gained an invaluable advantage over traditional businesses, which makes them more competitive and significantly enhances their development paths. New technology-based firms apply different approaches to their growth strategies. Investors measure them by their orientation to develop their client base, the scope of their services, sustainability and structure of income [McNally, 1995]; that all thanks to new technological advantages can be scaled up without applying proportionally bigger resources. These factors make the new 'gold rush' spread across cities and continents. Investors believe that finding the right start-up at the right moment (when its business model is already validated on the market, but its shares are not diluted among other investors yet) translates into a satisfying return on investment.

Summing up, start-ups, thanks to their openness to innovations, bring us closer to the future or rather bring the future to us sooner [Thiel, 2014], as they create technological shortcuts. The investor believes that the founder understands the market, the product and the target customers. The entrepreneur, then, is convinced that is on the threshold of wealth and thanks to additional funding, she or he will reach that point sooner. Such mutual trust has resulted in complete new schemes of employment and career development, as well as investment relationships. 


\section{Potential investment risks}

Despite being perceived as a very precious opportunity, new tech-based companies bear multiple risks that are exceptionally important in terms of them being investment projects. The main ones stem from the lack of financial information.

First of all, start-ups, due to a lack of business track, are difficult to examine. For the same reason, it is not common that they would undergo a due diligence check [Atherton, 2012]. During their first few months, start-ups go through the phase of concept formation, when it is extremely difficult to detect tangible signs of the future value of the company. Secondly, when it comes to the valuation of such an enterprise during its early days, it is often based on intellectual assets rather than physical capital, which causes difficulties with conducting such process [Coleman and Robb, 2012]. It is the reputation of the founders or presentation of the potential market opportunity that may influence the imagination of investors, rather than factual financial results. Thirdly, start-ups, thanks to technological accessibility, are able to create tools and devices that enter the market as a novelty. Thus, forecasting the potential customers' need and estimating the future demand in specific numbers is a backbreaking task as a such good is non-existing on the market.

Multiple things, including the money-centered above-mentioned factors, can influence the future financing path of a startup. The first two are internal to the structure of a company, while the latter comes from the outside environment. In order to structure the analysis, the author follows the division presented in the Table 1.

Table 1. Division of internal and external growth factors

\begin{tabular}{|l|l|}
\hline \multicolumn{1}{|c|}{ Internal factors } & \multicolumn{1}{c|}{ External factors } \\
\hline Founder and the team & Timing \\
\hline Viable product-market analysis & Start-up ecosystem \\
\hline Business model & Legal environment \\
\hline Financial plan & International expansion \\
\hline Implementation/Execution & Competition landscape \\
\hline & Little investors' interest/conflict \\
\cline { 2 - 2 }
\end{tabular}

Source: own compilation.

\section{Internal factors}

Start-ups are young companies that have had little time to establish their internal procedures, company culture or its position on the market. With little operational experience, limited resources and often unknown direction of its development, start-ups are prone to non-linear growth and probable pivoting. Such processes and events bear risk, but also 
provide opportunities that make this kind of ventures unusually profitable. In fact, most of the internal factors could be taken by two: for the benefit or the loss of the company.

\section{The founder and the team}

Especially at the initial stage, when the track record is mere, one of the main criteria the investment is being decided on is the human capital: the founders' experience, education and motivation [Peña, 2002], as well as all the team members' resumes, previous business activities, financial and technological literacy or even their networking and PR potential. Actually, their social capital, which translates into the amount and quality of relationships and ties that they are able to maintain with future investors, partners and customers, is absolutely crucial for the whole start-up growth process [Curtis et al., 2010]. Judgment of all that is extremely difficult and looks more like the work of an alchemist. The founder (s) are the driving force of the start-up, which means that their knowledge, ability to cooperate under agreed conditions and to outperform the expectations for the common interest are extremely significant for the future of the company. These potential powers have been in more detail explained in the work of Mayer at al. [1995] and divided into competency trust, conceptual trust and goodwill trust.

Moreover, Silicon Valley investors are known for picking entrepreneurs with Stanford or Harvard diplomas, which is supposed to be a guarantee, or rather an easily verifiable criterion, for their skillset and visionary mind. Many may find it surprising, considering the fact that multiple worldwide operating corporations have given up on university degrees as an employment requirement. However, research has proven that entrepreneurs with a managerial background - especially with MBA diplomas - translate into a faster growth of the company. Undergoing such a specific set of courses provides graduates with both high-quality education and self confidence that are indispensable on such a career path [Curtis et al., 2010]. Another research conducted by Neil et al. [2017], highlighted, among others, traits like self-efficacy, risk propensity and tolerance to ambiguity and basing on them also divided entrepreneurs into opportunity creating and opportunity seizing. Successful founders are able to spot an upcoming opportunity well ahead of their competitors as they observe the market from a cognitive perspective, which allows them to bring a meaningful differentiation to future products from the existing ones. They understand the dynamics and bring cutting edge solutions [Kirley, 2016].

Start-ups are bottom-up built organisations, composed of energetic alpha personalities, which in fact poses a risk of conflicts, crossover of ideas or misunderstanding of one another's role. As personal or emotional it may sound, most young companies encounter this sort of issues. Large companies are fitted out with whole Human Resources departments that aim to find the most suited employees with the most adjusted skill sets for each appointed position. On the contrary, in most start-ups the team members are either the co-founders or are recruited by them. Their experience in hiring is rather modest and so is the budget that can be spent on searching for the perfect fit. Such an inefficient role disposition leads to a lack of skills in certain fields, conflicts and finally to poorer performance. 
Last but not least on the team matter, building and developing a start-up is a frustrating activity with a postponed reward. Although the non-monetary motivations are the most significant factors for entrepreneurs [Alstete, 2008], various temptations like other job offers, obstacles like a lack of funding, multiple rejections from customers or growth smaller than ambition predictions await founders on their path to an exit. The start-up building process shifts from curating the product itself to resources management. Being a founder means being able to perform the undoable and to spot hidden opportunities [Curtis et al., 2010 [. Such pressure leads them to being very prone to mental diseases because of the responsibility, high expectations and extremely stressful conditions of work. Highly energetic people need a lot of positive and repetitive stimuli that easily wear off [Alstete, 2008]. On this rocky path, people who do not possess traits necessary for being an entrepreneur will most likely fail. In fact, only a small percentage of people is able to take up the entrepreneurial career, which is regrettable because the so-called serial entrepreneurship is another factor increasing the probability of the company's success [Curtis et al., 2010] as representatives of such an attitude have a very holistic approach to the market and a strong product awareness.

Inexperienced investors are not aware of this factor being crucial. Different investing agents attach various degrees of significance to it, however, especially those who are interested in a company at its initial stage, have to rely on the founders' experience and potential. The fact is that at every stage of development, the more qualified human capital involved, the more expensive will be the equity for future investors [Coleman and Robb, 2012]. However, the assessment process is still troublesome, as everything comes down to trust and reputation, which are extremely difficult to quantify [Panda and Dash, 2013].

\section{Viable product-market analysis}

It is not surprising that start-ups lack all types of resources: people, funding, time and often specific tools. For the most of their lifespan, the driving force behind the company seems to be the innovative idea of the visionary founder. The hazard of such circumstances is that the CEO may neglect existing competition or future implementation risks. It is crucial that the team is fully aware of the customer demand risk [Skarzynski and Schaedler, 2010]. The analysis should include an in-depth investigation of the existing companies within the field, potential size of the market and future capability of the product or service [Alstete, 2008]. Moreover, the risk can be mitigated using the open innovation method, experiments and future-back mapping method [Skarzynski and Schaedler, 2010].

The market analysis must be accompanied by a profound product examination and planning using the most apt strategic approach. Kirley [2016] described different manners of performing it: the transcendent-based approach which puts an emphasis on the superior quality of an already existing product and brings it to another level; product-based approach that brings a new good to the market; user-based approach focusing on the customer's needs, while manufacturing-based approach draws attention to resources and makes use of production standard. 
Unless the investor is a well-informed and professionally engaged specialist within the field or a structured fund orders a proper (often costly) market analysis, there is a vast field for manipulation or unjustified enthusiasm that besots the rational assessment of the situation. Little research and a lack of market awareness lead to financial losses, thus, it is a very significant factor for being selected to become funded, especially at the initial stage of growth when there has been little opportunity to test the hypothesis.

\section{Business model}

The business model is strictly connected with the previous point. It is a sort of an engine for the start-up as it is the combination of all the components and resources that allow the company to approach the market and achieve its goal: making profit by finding its comparative advantage. It includes information on the managerial logic, competitive advantage and further strategic development of the venture, as well as description of partners' or market opportunities and risks [Ziółkowska, 2018]. Morgiono et al. [2017], basing on the resource dependency theory, brought its definition down to a 'set of available tactics' that strengthens the autonomy and legitimacy of the company. Together with the customer demand risk, product development risk and competition risk, the lack of profitability stemming from a poor business model is the most important hazard for the nascent company [Skarzynski and Schaedler, 2010].

Its aim is to serve as a bulletproof but flexible foundation for future entrepreneurial operations and to indicate the most profitable directions of development. A careful analysis of its components allows future investors to understand the logic driving the business to the effects desired by all the stakeholders.

\section{Financial plan}

Financial outcome is not the only criterion start-ups are judged on as there are other indicators like speed of growth in terms of the number of users or the user's lifetime value and degree of activity, but for sure it is the most common one. Hence, a promising but realistic financial broadcast is eagerly taken into consideration when assessing a start-up's potential. A business plan is the effect of the theoretical analysis (market investigation and business model preparation) combined with practical application to current economic conditions and market opportunities. It serves as a Key Performance Indicator (KPI) or Objective Key Result (OKR) that can be easily measured and verified basing on selected milestones.

Realistic financial assumptions are undoubtedly the basis for most investment contracts because they speak clearly about the outcome both sides are interested in. The degree of detail may differ according to various needs of investing agents and stages of development. Most institutional investors draw more attention to meticulous planning, while business angels have less strict expectations to future results. Mostly because of their know-how and ability to surveil the team and its progress on a regular basis. Nevertheless, whenever funding process is launched, the business plan is the first factor of assessment. 


\section{Implementation/Execution}

For the need of this article, the author assumes that a start-up goes through four stages of development: concept formation, amassing of resources, product development and business growth [Papadimitriou and Mourdoukoutas, 2002], which will be explained later on in this article. While they differ from each other in many ways, they all have one thing in common: need for further development and thus funding.

During different phases of growth, start-ups have at their disposal either a non-existing proof of the concept and a mere vision or a well-developed widely-tested pampered product. For the latter, it is a no-brainer to attract funding, however, for the former the plan of implementing the product to the market may be one of the crucial factors for potential investors [Blank and Dorf, 2012]. Moreover, it is even more difficult and complex when one has to prove the need of a good or service that has not been yet introduced to the wider group of users. Such an issue is especially hard when one takes into consideration that most start-ups are focused on technologically-advanced products that have had little market exposure and not much chance to gain thousands of dedicated users.

Therefore, it is important for founders to be able to prove their executive skills. For this reason, their previous experience is crucial as an undeniable sign of their ability to manage the company and deliver the agreed milestones [Curtis et al., 2010]. Those can be applied to different fields: marketing, product development or customer bases. All of these areas demand specific expertise or/and a large degree of determination in execution, about which investees are investigated by all kinds of investors.

\section{External risk factors}

\section{Timing}

Many researchers have appointed timing and specific market or social trends as success or risk factors. This idea of timing as a prevailing cause of success or failure was firstly proposed by Bill Gross in his famous TED Talk in 2015 (The single biggest reason why start-ups succeed). It may appear as a very controversial idea (or called 'luck'), but it is strictly connected to a viable market and product analysis, which can, to a significant degree, eliminate this hazard. As astonishing or irrational as it may seem, it has been proven a fact by many startups which have risen on the wave of shared economy. Today's unicorns like Airbnb or Uber are flagship examples of concepts that gained popularity after the hit of the global financial crisis when people started to be more eager to share their space and belongings in exchange for additional income.

As much as all entrepreneurs and investors would like to possess a foretelling crystal ball that would provide information on the upcoming 'next big thing', it is unfortunately impossible to predict it with a hundred percent certainty. Timing may work in favour of the project or may squander the efforts and resources dedicated to a project. 


\section{Start-up ecosystem}

Many advocate that a healthy start-up community and cultural settings massively help both the existing companies and those that are to be freshly launched. The so-called leaders, feeders and cheerleaders allow start-ups to successfully grow. The former group are founders - A type personality entrepreneurs, who possess a clear vision and gather resources to set up a company. The feeders' group is composed of accelerators, incubators, universities, investors, corporations and institutions willing to support the leaders with all sorts of infrastructure and resources they have at their disposal. The latter cohort are those who bear interest in the product, are eager to become early adopters and will spread the word about the start-up in the future [Feld, 2012].

Creating such an ecosystem is a non-linear backbreaking task that takes decades to materialise without a guarantee of success. The world-known Silicon Valley is the most famous start-up community which does not cease growing. In fact, thanks to its reputation, it keeps on acquiring talent and funding, as well as it gains evermore visibility with each successful venture of which it is ample.

Having such an ecosystem in place is a massive support for existing and future companies because it serves as a sort of safety net in case of a lack of any kind of resources. However, investors do not always take this factor into consideration when judging the potential success of a company.

\section{Legal environment}

Technology outruns the legislation as it continuously creates new opportunities for users to satisfy the need they were not even aware of having and for entrepreneurs to make profit. Especially medical devices (MedTech) and concepts from the financial sector (FinTech) have become the bone of contention for most legal systems. The whole cryptocurrency market has caught most governments as a surprise and until today has figured as an unclear concept, with only a few markets like Malta or Germany being ready for such procedures [Wolfson, 2018]. The dominant taxation policy, trade conditions, degree of government interventionism and monetary policies all have an influence on the technological advancement and start-up environment [Kirley, 2016].

As a clear example of a simply applicable, tax favouring scheme provider can serve Singapore. It gives a full exemption from tax for the first 100000 USD and 50\% exemption on income up to 200000 USD during the following three years [Enterprise Singapore, 2019]. Others, like the United Kingdom or France are comparatively more eager than other European countries to encourage venture capital funds and business angels to invest in small and medium-sized enterprises by introducing various kinds of tax incentives [European Commission, 2017].

This is a support factor for the previous point. Attractive legal conditions create stable fundaments for creating a solid and healthy start-up community that convinces the investors to put money in the given market. 


\section{International expansion}

Sounding like an opportunity, this part of start-up development often turns out to be very troublesome. It is part of the natural journey and inevitable step that every company undertakes in order to conquer the bigger part of the cake. However, with the whole complexity of the process - mainly difficult cultural and economic contexts of each new market, various customer needs and legal specificities - entrepreneurs often fail to introduce their services and products to the perspective marketplaces [Sutton, 2014].

An idea that looks like a chance, in fact, can slow down the growth or ruin previous efforts. It is a very costly challenge and gives no guarantee of return on investment. One could compare it to the whole new company establishment process with, among others. all the legal procedures and hiring struggle.

\section{Competition landscape}

A well-prepared founder has done an in-depth landscape analysis prior to launching the building process. However, the dynamics of start-up environments are impossible to follow ceaselessly, while actually only by monitoring it constantly one would be able to make sure no threatening novelties have been released in the meantime. The Silicon Valley myth says that on average there are six people on the globe working on the same exact innovative idea at the moment.

Let alone creative minds from all over the world, there is a risk of being copied and outperformed by bigger, more resourceful and more experienced market players. Therefore, it is crucial for start-ups, and as well for investors, to make sure that the entry barrier limiting the access to the specific customer (and his or her wallet) is difficult for other start-ups to reach over and pilfer. It can be embodied as a specific know-how, well-prepared branding, network or physical equipment that is unprofitable to duplicate.

Start-ups are often obsessively reluctant to share their idea and demand a non-disclosure agreement signature before accepting to sit at the table with potential partners or investors. The sad truth is that despite their rational approach, they stand little chance when confronted with a corporation's army of lawyers or extremely money-sensitive investors willing to grasp the innovation.

Hence, entrepreneurs, and investors supporting them should stay aware, alert and ready to act in terms of their competitors' activity, but nonetheless, they will have little certainty of safety.

\section{Little investors' interest or conflict with investors}

Start-ups find financing as a constant challenge. Despite lean management and reasonable spending policies supported by innovative managerial tools, the burning rate leads to the inevitable abyss of non-liquidity or even debt. Obtaining a grant, a round of funding or attracting a new investor are all short-term solutions that do not predestine the future of the company. 
Financing is tricky no matter the stage of development. At the beginning a lack of the proof of a concept minimalizes chances to win an investor, yet as the company grows, the sums needed to support it skyrocket and lessen the funding opportunities.

Most start-ups encounter the financing gap between the first and second phase and then between the third and fourth one. The first spread occurs due to the fact that before the validation of the product, even very audacious venture capital funds find it too risky to invest. The second gap appears because of the stock exchange requirement and fees.

Figure 1. Start-up stages compared to the size of financing

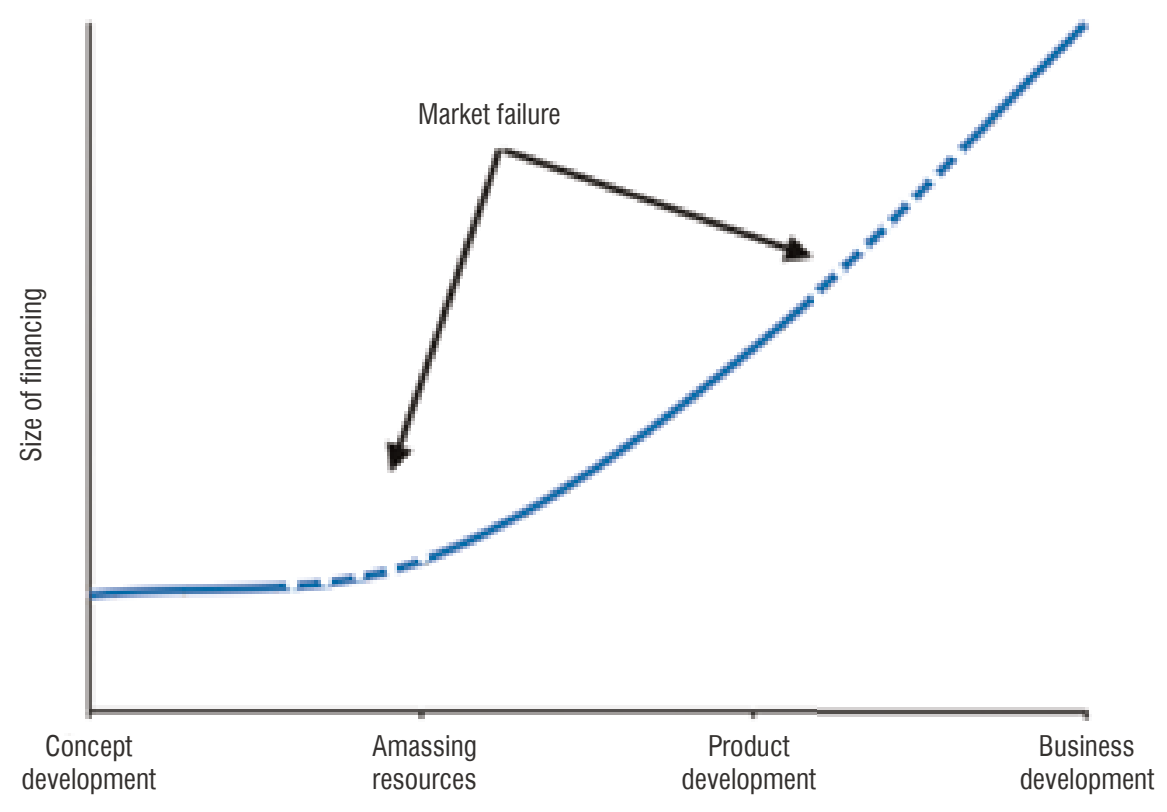

Start-up stages

Source: Papadimitriou and Mourdoukoutas (2002), p. 5.

\section{Stages of development}

A solid overview of investing agents deserves an explanation of the growth process in a start-up. Future funding is tightly connected to the development stage of the young company because different types of investors focus on enterprises in their various forms. As becoming a shareholder becomes less risky with time and growth progress, at the same time is gets more expensive and more difficult.

There exist many concepts dividing the development into specific stages that a young technological company goes through. Most of them go from three to seven. Despite the difference in numbers, in general, they describe the same process. 
Table 2. The summary of different approaches to start-up development stages

\begin{tabular}{|c|c|c|c|c|c|c|c|}
\hline $\begin{array}{l}\text { No of } \\
\text { stages }\end{array}$ & \multicolumn{7}{|c|}{ Name of the stage } \\
\hline 3 & \multicolumn{2}{|l|}{ Early Venture } & Series A stage & \multicolumn{4}{|c|}{ Growth Stage (Post Series A) } \\
\hline 4 & \multicolumn{2}{|l|}{ Prototyping } & Customer Base & \multicolumn{3}{|c|}{ Market Expansion } & Exit \\
\hline 4 & $\begin{array}{l}\text { Concept } \\
\text { Formation }\end{array}$ & $\begin{array}{l}\text { Amassing } \\
\text { Resources }\end{array}$ & $\begin{array}{l}\text { Product } \\
\text { Development }\end{array}$ & \multicolumn{4}{|c|}{ Business Development } \\
\hline 5 & $\begin{array}{l}\text { Seed and } \\
\text { Development }\end{array}$ & Start-up & \multicolumn{2}{|c|}{ Growth and Establishment } & \multicolumn{2}{|l|}{ Expansion } & $\begin{array}{l}\text { Maturity and } \\
\text { Possible Exit }\end{array}$ \\
\hline 6 & $\begin{array}{l}\text { Concept and } \\
\text { Research }\end{array}$ & Commitment & $\begin{array}{l}\text { Traction/ Validation } \\
\text { Refinement }\end{array}$ & Refinement & \multicolumn{2}{|l|}{ Scaling } & $\begin{array}{l}\text { Becoming } \\
\text { Established }\end{array}$ \\
\hline \multirow[t]{2}{*}{7} & Seed stage & Start-up stage & Growth stage & $\begin{array}{l}\text { Established } \\
\text { stage }\end{array}$ & $\begin{array}{l}\text { Expansion } \\
\text { stage }\end{array}$ & Decline stage & Exit stage \\
\hline & \multicolumn{7}{|c|}{ Consensus agreed by the author } \\
\hline 4 & Seed Stage & & Validation Stage & Growth Stage & Expansion & e (with potentiz & | Exit) \\
\hline
\end{tabular}

Source: Dibner (2018); Cohan (2016); Petch (2016); Segal (2018); Zahorsky (2019).

\section{Seed stage}

The seed stage describes a start-up when it is just an idea or a concept to be developed and verified in terms of its commercial applicability. Founders focus on research around the industry and aim to find their niche. Once convinced to have found their targeted audience and verified the market readiness for the product, founders search for specialized team members whose skills match the needs of the future process. Most of the time infrastructure is not yet in place. First things that are established are a business plan, mission statement, processes and market analysis. These are indispensable parts of the process, however, they are not directly translated into tangible products without efforts and determination of qualified founders.

The aim of this stage is to build an MVP (Minimal Viable Product) and secure basic funding until the start-up is eligible for significant external funding. It is important to keep in mind that the cost of development of the product and its business launch is twenty times higher than the initial R\&D spending [McNally, 1995]. Having a working product, the company is able to earn income from first customers and suppliers or run enough tests to obtain a governmental grant. Nevertheless, most entrepreneurs at this phase rely on bootstrapping, i.e. they base on their personal financial resources or on the so-called three Fs - family, friends and fools. Other sorts of investors are usually interested in larger-scale ventures. At the seed stage start-ups encounter too high a product and engineering risk with too little proof of efficiency on the market. On the other hand, investors encounter the liability of newness [Das and $\mathrm{He}, 2006$ ] and in fact one of the most demanding challenges at this stage is fast learning.

\section{Validation stage}

This stage normally starts after a year from a start-up's first activity. The growing customer base allows the company to keep their cash inflow at least on a steady level, with the goal 
of obtaining recurring revenues, while attracting more paying users. Additionally, thanks to ongoing feedback, the product becomes more efficient and tailored to customers' needs.

At this stage, the start-up has its business model figured out and its main challenges focus around scaling, hiring and product development. Gaining more users demands an efficient marketing strategy and resources to implement it. Attracting skilful employees is crucial in multiple fields, especially management, accounting, the aforementioned marketing and product engineering. The latter is particularly significant at this stage, because the company should already have a proven product ROI (return on investment).

During the validation phrase, the company still operates on its own earned profit, bank loans and grants (from the government, a partner organisation or an accelerator) with first prospects on Business Angels.

\section{Growth stage}

Surviving until this stage means that the product is more than a promising market fit with a profitable margin on its sales. The company certainly has gained customers' trust and more credibility, which strengthens its position towards the competition.

Structures grow: professional sales, deployment and support teams are already in place. Certain processes are automated or outsourced. The founders keep a close eye on acquisition metrics and profit growth, while being very vigilant on what the competition is at. The main challenge is to follow the vision and to create an implementable plan. The most successful founders think of the bigger picture and stay hungry for a bigger slice of the cake.

The growth stage opens more financing options like Venture Capital funds, investors and Business Angels. Certainly, having a viable product makes the start-up eligible for all sorts of grants and bank loans. The later the company has decided to give away its shares, the more expensive they will be in the upcoming periods and more eager the potential investors will be to join the team.

\section{Expansion stage}

An established company can grow in various aspects. It may translate into a horizontal expansion, meaning grasping a bigger market share. Also, a start-up can disperse its focus on a wider range of products or develop its products along the supply chain, which means a more horizontal expansion.

The former usually means entering foreign markets, which encounters more hiring and product challenges. Employing a local representative and adjusting the device or software to the unknown needs of the new group of consumers is costly in financial and human capital terms. The latter translates into new products and novel distribution channels, which in fact as a process itself is as engaging as starting up a new business - with the difference that there are funds, the structure and the brand in place. Which, thankfully, makes all the difference in the world. 
At this phase, the company needs to grow aggressively in order to prove its place on the market and to become tempting for partners, investors or possibly future stocks if planning an IPO as its exit strategy. Such an ambitious plan leads to psychological and financial challenges that accompany this operation. The founders are especially motivated at this stage because of the upcoming reward that has never been so close. Selling a well-functioning company is the aim (and the most common scenario) that most entrepreneurs work hard for, with single exceptions like Jeff Bezos of Amazon or Jack Ma of Alibaba, who decided to stick to their roles for decades.

\section{Analysed investing agents}

As emphasised by the author in the first part of the article, start-ups are very specific investment projects. While offering a promising return on investment, they are rather ungrateful objects of valuation. Despite a careful analysis of all the potential internal and external factors, the trajectory is often non-linear, and the situation stays volatile through most of their lifetime. Despite such a hazard, the interest grows from multiple sides: private and institutional investors, governments and corporations.

Most of the investing agents are driven by the temptation of wealth, others, like governments, by their mission to fish out the most innovative ventures that will influence the country's economy in the long-term or corporations that search for solutions they could acquire or apply within their company to outperform the competition. Young technological companies have proven that they can be a grateful investing material that brings promising returns and publicity. It is not only proven by the volume of dollars pumped into new companies, but also by an increasing number of methods of investment and investing agents themselves. Different markets have various proportions of shares of each of them, for example the American market is much more VC-centric comparing to Europe, where such funds have massively sprouted only during the last couple of decades.

Below the author will present an overview of the investing methods that are most often analysed and presented in the literature.

\section{Bootstrapping and loans}

Every start-up is built on faith the founder has in it. Most of them are irrationally determined and willing to sacrifice all the resources they possess at their disposal: savings, free time and contacts. Not all the entrepreneurs are able to build their product themselves and when at the seed stage, they either charm another skilled co-founder with their vision, or they spend their personal funds on outsourcing the service. Instead of dedicating their individual savings, they often rely on the so-called 3Fs - family, friends and fools - in general, anyone who is eager to get involved and help the company grow. The so-called hybrid entrepreneurship [Thorgren et al., 2014] is also very popular at the initial stage. It simply means keeping 
a stable salary job and spending after-hours building a start-up, which is surprisingly common. Four out of five new founders launch their ventures when still in a paid employment [Strategic Direction, 2015].

Even more convinced entrepreneurs, when faced with a lack of funding, reach out to banks and financial institutions for loans. However, such support is very popular among more mature start-ups, too. The main difference is that at the initial stage, the commitment is charged on the physical person and later on, when the company is set up and gains the legal entity, its financial history and value in order to be able to take loans. At the start there are modest assets to be used as a collateral security, while later on there is a company with its intellectual property and financial history [Coleman and Robb, 2012]. Banks also find it difficult to differentiate good from bad technological ideas, hence they turn down most of the loan applications [McNally, 1995].

In general, all sorts of bundling patterns are very popular. It means that founders use three to five different financing methods. Researches show that a single method is in fact very rare [Atherton, 2012].

\section{Crowdfunding and crypto offering}

Start-ups at two first stages of development can rely mostly on their concept and vision to develop them. Crowdfunding is a financing method that allows taking advantage of the imaginative founder and his or her growth hacking marketing strategy. Additionally, a crowdfunding campaign is a bulletproof product validation and often a pre-sale campaign. Even resourceful companies at times decide to run such projects in order to create the buzz and earn popularity. Crowdfunding offers an amazing opportunity for start-ups because it allows them to acquire money without diluting its shares.

Another way of crowdfundingis the relatively novel initial coin offering (ICO), stable coin offering (SCO) and security token offering (STO). They are all diverse forms of gathering funding in exchange for a privately issued token - based on blockchain technology. The latter is, despite the buzz, not the most innovative, however, it ensures security, anonymity and transparency, which are crucial for gaining trust, as well as they create an uncommon investment opportunity for those willing to stay unnoticed. The market shows that ICOs are available to mature multinational companies (e.g. Kodak) and to start-ups even at the very initial stage. At least such was the case at their golden age (2015-2017), because they mostly require a solid description of the cryptoeconomy in their white paper and a credible team. Nowadays, the concept of the ICO has worn off and crypto offering drifts towards STOs, which offer a token with a guarantee of an actual prospering company behind it.

\section{Governmental grants, accelerators, corporate funding and support}

Institutional funding draws interest in start-ups on multiple stages of development. At the very seed stage, when costs are exiguous and the proof of the concept is not yet in place, the founders look out for rather modest grants that are spent on the product itself. Many 
accelerators and incubators (both independent and built within corporations) offer contests for technological companies, where winners are rewarded with mentoring, coupons for necessary services or finally financial funding. While a start-up grows, so do its needs. More infrastructure and know-how is in place and it raises costs massively.

While independent accelerators are built by volunteers with no specific agenda or by investors themselves, who hope to scout the most promising ventures in order to earn a handsome ROI, there are ones inside corporations (Corporation Venture Capital - CVC) that are driven by more strategic goals. These are more often interested in fresh ideas and public branding. In return they offer credibility, technical support, managerial advice, market information and much more (as shown in Table 4). They nurture the start-up and assist at decreasing the growth risk [McKnally, 1995]. Their aim is to create a freestanding business.

Table 3. Benefits for investee firms that have arisen as a result of direct CVC finance (apart from the provision of finance)

\begin{tabular}{|l|c|}
\hline \multicolumn{1}{|c|}{ Resource } & Number of mentions \\
\hline Help with short-short-term problems & 19 \\
\hline Access to corporate management expertise & 16 \\
\hline Credibility & 16 \\
\hline Access to corporate technical expertise & 11 \\
\hline Pricing benefits & 10 \\
\hline Lower performance targets & 9 \\
\hline Access to corporate marketing/distribution networks & 9 \\
\hline Extra production/R\&D support & 8 \\
\hline Opportunity to establish further business relationships & 8 \\
\hline Access to more sophisticated financial control systems & 1 \\
\hline Access to corporate office space & 1 \\
\hline Access to possible exit routes & 1 \\
\hline Synergy & 1 \\
\hline Enhances attractiveness to other investors & 1 \\
\hline Stability & 1 \\
\hline Access to corporate expertise & 1 \\
\hline Streghtening of vertical relationships & 1 \\
\hline
\end{tabular}

Source: McNally (1995), p. 25.

Rewards and institutional grants are even more attractive due to the fact they most often they are not loans, but actual endowments. The most common hidden catch they include is the fact that in order to obtain them (especially European Union grants), an applicant must show his or her own financial input - usually around 20 to 30 percent. Also, the settlement is encumbered with burdensome procedures and detailed explanations that cause additional workload demanding to be dealt with by specialists. 
There have been observed different models to the grants distribution. For instance, in the United States, the government has become a passive partner to venture capital, meaning to support a fund financially in their own investment schemes. The government in Tel-Aviv served as a catalyst for investors as it not only provided funds for research and technology incubators, but also took direct equity positions in selected ventures. In Ireland, the VC funds were not only established and managed by the government, but indirectly it took equity in chosen start-ups and was actively involved in all the processes enabling the future growth [Papadimitriou and Mourdoukoutas, 2002].

\section{Business Angels}

Business Angels are private investors, who offer the so-called smart money, that is not only funding, but also added value in the form of know-how, network, mentoring or less likely, but possible, actual involvement in the process of development. They represent value mostly in financially oriented fields than product and technology focused concepts. Business Angels may serve as a sounding board, which is beneficial for investees, but also give the investor a feeling of closer control [McNally, 1995].

Thanks to their experience and hands-on engagement, they are eager to invest in start-ups sometimes even at the middle stage, or more commonly at the growth phase. They look out for investments whose shares are not very diluted yet, before series-A and, as research in the US proved, they are more interested in high-tech business [McNally, 1995]. Contrarily to some opinions, according to the research, Business Angels on average make around $27 \%$ of annual ROI when investing in 50 start-ups or more per year ( $90 \%$ of that earning is concentrated in $10 \%$ of ventures) [Wiltbank, 2013].

Afterwards, getting involved is more costly and as mentioned below, Business Angels take advantage of their knowledge, so it mitigates the costs of shares. Also, start-ups at more initial stages are more interested in this kind of investors because they cannot afford acquisition of top managerial talents for each of the crucial fields that the company relies on when growing. At this moment, partial involvement of an experienced mentor allows the founders to survive.

\section{Venture Capital funds (VC)}

Venture Capital funds (or so-called limited partnerships) are wealthy companies with proper structures focused on three activities: fundraising, investing and exiting [Klonowski, 2006]. They serve as a bridge or an intermediary between investors and investees basing on the supply and demand [Panda and Dash, 2013]. It is a tough nut to crack as they have to perform marketing, to both sides: the financial backers and to future investees, as well as to maintain long-term relationship with them [Robie and Murray, 1992]. They exist in order to find startups, get involved at the earliest but surest stage that will finally guarantee a successful exit or acquisition. Contrarily to corporations or governmental institutions, an optimal acceleration in order to win the-bigger-the-better ROI is their only goal and raison dêtre. The process is complex because 'venture' means risk. Therefore, they employ the most skilful analysts, 
seek diversity in their portfolios, apply best valuation methods, take much time to perform a proper due diligence process and most importantly, negotiate very strict contracts with founders. Willing to invest millions, they need to secure their funding and eliminate the risk as much as possible.

Venture Capital (VC) fund managers, disposing their investors' money, are thus carefully scrutinized for their decisions and performance. In order to protect themselves, they apply complex procedures and restrictions. Starting with a deal origination, screening, evaluation and structuring in order to continue with post investment activities [Robbie and Murray, 1992]. They attempt to diversify their portfolios in order to fight the unsystemic and firm-specific risk [Bartkins and Hassan, 2009]. However, as much as they cover the interests of investors, in the past they used to not always guarantee the additional value for start-ups. Today, they seem to understand better and better that they have to be phenomenal contextual strategists [King, 2013]. There are types of hands-off and hands-on investors, but it gets more frequent that VCs also intervene more profoundly in the company's structure and management. Many have understood that start-ups pass from the exploration stage until a stable business model is put in place to the exploitation stage, when tasks become more repetitive and the focus shifts to scale up. Knowing this, there is a demand on the investor's side for a specific CEO [March, 1991].

Investments by VC can be structured as debt, equity, convertible securities or any combination of these. Mostly the investment is in exchange for interest bearing debts and stock conversion rights, yet it depends on the philosophy of the fund. Most investors get involved in three to seven years with a hope to start cashing out in the fourth or fifth year [Taylor, 1989]. Venture capital investment became attractive because historically it had no correlation to volatile stocks and bonds whose value would fluctuate [Fried and Hisrich, 1992].

Some funds try to differentiate from others by gaining a specialised industry knowledge, which allows them to develop bonds within given fields. Others diversify their investments across stages of development. None of the strategies appear to be bulletproof, however, specialisation in a single phase of growth shows a negative outcome [Bartkins and Hassan, 2009].

However, only mature and functioning companies dare to approach venture capital funds. Such an encounter demands from founders experience, an ability to handle the negotiation process and vast financial and legal knowledge. VCs mature similarly to start-ups: they go from the creation stage, through the momentum stage and then to maturity, while facing similar obstacles and challenges [George and MacMillan, 1985]. This means that the ones being the longest in place and having unicorns in their portfolios draw the most attention of start-ups.

\section{Summary}

Literature research reveals that new technology-based firms demonstrate different financing patterns at different stages of development. On the one hand, funders, in order to diversify their portfolios, do not limit themselves to one single growth phase. On the other 
hand, audacious founders, in order to acquire investment, are open to various sources and do not restrain themselves from using multiple of them at the same time. The presented table of financial matches between methods and stages is a result of a literature review, which requires a further empirical verification, yet constitutes a valuable starting point for further research.

Table 4. The matching of financing methods with different stages of start-up development

\begin{tabular}{|l|c|c|c|c|}
\hline \multicolumn{1}{|c|}{ Financing method } & Seed stage & Validation stage & Growth Stage & Development stage \\
\hline Bootstrapping & $\checkmark$ & $\checkmark$ & & $\checkmark$ \\
\hline Loans & $\checkmark$ & $\checkmark$ & $\checkmark$ & $\checkmark$ \\
\hline Crowdfunding & $\checkmark$ & $\checkmark$ & $\checkmark$ & $\checkmark$ \\
\hline Crypto offering & $\checkmark$ & $\checkmark$ & $\checkmark$ & $\checkmark$ \\
\hline Governmental grants & $\checkmark$ & $\checkmark$ & $\checkmark$ & $\checkmark$ \\
\hline Accelerators & $\checkmark$ & $\checkmark$ & $\checkmark$ & $\checkmark$ \\
\hline Corporate funding and support & & $\checkmark$ & $\checkmark$ & \\
\hline Business Angles & & & & \\
\hline VC funds & & & $\checkmark$ & \\
\hline
\end{tabular}

Source: own compilation.

\section{Further research}

Figures and statistics confirm that there is a massive surplus of funding on the market. VC investment reached the level of 67 billion USD in the United States and 148 billion USD globally [Meisler and Cannon, 2018]. In Europe, the introduction of the Lisbon Strategy is a guarantee of a significant inflow of funds for tech-based companies. The investment rage does not slow down. However, the heart of the matter lies in funding distribution. Not every industry, not every founder, every product meets the opportunity to obtain funding. Paradoxically, companies need financing the most when they are the most vulnerable and least certain to grow (as shown in Figure 1) between the stages. It is the beginning and middle of a start-up's development process when the lack of money is most acute.

Despite the abundance of funding agents and inflow of cash, not every start-up community will flourish and assure support to all potential future 'unicorns. There are several reasons for such uneven distribution. Firstly, it is difficult, or even impossible, to predict the upcoming trend. For this reason, a lot of funding gets misplaced and in fact wasted. Secondly, the recruitment process is far from being flawless. There are procedures that may give an illusion of certitude but in fact they fuel an inefficient system. Thirdly, start-up founders are overly optimistic visionaries and may often misguide an investor when it comes to making a decision. There are thousands of technological companies that deserve support but due to type-B personality or less educated owners, they are unable to convince the investors, especially at the seed stage. 
Start-up financing patterns are not perfectly efficient and no matter how much funding will be poured over young technological companies, the results are impossible to be predicted with certainty. Most investing agents agree that the process reminds 'the blind man's bluff' because on both sides there are human beings with their emotions, gut feelings and pre-existing assumptions.

\section{References}

\section{Books}

1. Blank, S., Dorf, B. (2012). The Startup Owner's Manual: The Step-By-Step Guide for Building a Great Company. K \& S Ranch.

2. Feld, B. (2012). Startup Communities: Building an Entrepreneurial Ecosystem in Your City. New Jersey, USA: Hoboken.

3. Ries E. (2011). The Lean Start-up. New York.

4. Thiel, P., Masters, B. (2014). Zero to One: Notes on Start-ups, or How to Build the Future. New York.

\section{Articles}

1. Alstete, J.W. (2015). Aspects of entrepreneurial success. Journal of Small Business and Enterprise Development, Vol. 15 Iss. 3, pp. 584-594.

2. Atherton, A. (2010). Cases of start-up financing: An analysis of new venture capitalisation structures and patterns. International Journal of Entrepreneurial Behavior \& Research, Vol. 18, Iss. 1, pp.28-47.

3. Bartkus, J.R., Hassan, M.K. (2009). Specialization versus diversification in venture capital investing. Journal of Financial Regulation and Compliance, Vol. 17, Iss. 2, pp. 134-143.

4. Beauchamp, M, Kowalczyk, A., Skala, A. (2017). Polskie Startupy. Raport 2017. Warszawa: Fundacja Startup Poland.

5. Blazenko, W., Pavlov, A.D., Eddy-Sumeke, F. (2012). New ventures start-up and technological innovation. International Journal of Managerial Finance, Vol. 8, Iss. 1, pp. 4-35.

6. Christensen, C.M., Raynor, M.E. (2003). The Innovator's Solution, Creating and Sustaining Successful Growth. Boston, MA: Harvard Business School Press.

7. Coleman, S., Robb, A. (2012). Capital structure theory and new technology firms: is there a match? Management Research Review, Vol. 35, Iss. 2, pp. 106-120.

8. Curtis, T., Herbst, J., Gumkovska, M. (2010). The social economy of trust: social entrepreneurship expeirences in Poland. Social Enterprise Journal, Vol. 6, Iss. 3, pp. 194-209.

9. D’Aveni, R.A., Gunther, R.E. (1994). Hypercompetition: Managing the Dynamics of Strategic Maneuvering. New York, NY: The Free Press.

10. Das, T.K., He, I.Y., (2006). Entrepreneurial firms in search of established partners: review and recommendation. International Journal of Entrepreneurial Behaviour and Research, Vol. 12, Iss. 3, pp. 114-143. 
11. Fried, V.H. and Hisrich, R.D. (1992). Venture Capital and the Investors. Management Research News, Vol. 15 Iss. 4, pp. 28-39.

12. George, R., MacMillan, I.C. (1995). Corporate Venturing: Venture Management Challenges. Journal of Business Strategy, Vol. 6 Iss. 2, pp. 85-91.

13. Iñaki, P. (2002). Intellectual capital and business start-up success. Journal of Intellectual Capital, Vol. 3, Iss. 2, pp. 180-198.

14. King, B.L. (2013). Succeeding in a hypercompetitive world: VC advice for smaller companies. Journal of Business Strategy, Vol. 34, Iss. 4, pp. 20-30.

15. Kirkley, W.W. (2016). Creating ventures: decision factors in new venture creation. Asia Pacific Journal of Innovation and Entrepreneurship, Vol. 10, Iss. 1, pp. 151-167.

16. Klonowski, D. (2006). Venture capital as a method of financing enterprise development in Central and Eastern Europe. International Journal of Emerging Markets, Vol. 1, Iss. 2, pp. 165-175.

17. March, J.G., Nerkar, A. (1991). Exploration and Exploitation in organisational learning. Organization Science, Vol. 2 No. 1, pp. 71-87.

18. Marigono, A., Zolin, R., Chang, A. (2017). A typology of social venture business model configurations. International Journal of Entrepreneurial Behaviour and Research.

19. Mayer, R.C., Davis, J., Schoorman, D. (1995). Social entrepreneurship: the case for definition. Stanford Social Innovation Review, Spring.

20. McGowan, P., Everett, K. (2012). Venture capital funds - recent European developments. Journal of Investment Compliance, Vol. 13, Iss. 2, pp. 57-59.

21. McNally, K. (1995). Corporate venture capital: the financing of technology business. International Journal of Entrepreneurial Behaviour \& Research, Vol. 1, Iss. 3, pp. 9-43.

22. Neill, S., Metcalf, L.E., York, J.L. (2017). Distinguishing entrepreneurial approaches to opportunity perception. International Journal of Entrepreneurial Behaviour \& Research, Vol. 23, Iss. 2, pp. 296-316.

23. Panda, S., Dash, S. (2013). Trust and reputation in new ventures: insights from an Indian venture capital firm. Development and Learning in Organisations: An International Journal, Vol. 27, Iss. 4, pp. 9-11.

24. Papadimitriou, S., Mourdoukoutas, P. (2002). Bridging the start-up quity financing gap: three policy models. European Business Review, Vol. 14, Iss. 2, pp. 104-110.

25. Robbie, K., Murray, G. (1992). Venture Capital in the UK. International Journal of Bank Marketing, Vol. 10, Iss. 5, pp. 32-40.

26. Skarzynski, P., Schaedler, D. (2010). A new model for unlocking the value of entrepreneurial businesses. Business Strategy Series, Vol. 11, Iss. 5, pp. 271-276.

27. Talaia, M., Pisoni, A., Onetti, A. (2016). Factors influencing the fund-raising process for innovative new ventures: an empirical study. Journal of Small Business and Enterprise Development, Vol. 23, Iss. 2, pp. 365-378.

28. Taylor, L. (1989). Raising Venture Capital. Journal of Business Strategy, Vol. 10, Iss. 4, pp.61-64.

29. The Secret to Entrepreneurship: business and pleasure: Exploring the passion for work and for running a business. Strategic Direction, Vol. 31, Iss. 7, pp. 11-12. 
30. Thorgren, S., Nordstrom, C. and Wincent, J. (2014). Hybrid entrepreneurship: the importance of passion. Baltic Journal of Management, Vol. 9, No. 3, pp. 314-329.

31. Ziółkowska, M. (2018). Determinants of choosing a business model in small and medium-sized enterprises. Journal of Management and Financial Sciences, Vol. XI, Iss. 34, pp. 93-101.

\section{Reports}

1. European Commission (2017). European Commission Final Report on Efectiveness of tax incentives for venture capital and business angels to foster the investment of SMEs and start-ups, TAXUD/2015. DE/330. Retrieved from: https://ec.europa.eu/taxation_customs/sites/taxation/ files/final_report_2017_taxud_venture-capital_business-angels.pdf [accessed: 20.01.2019].

2. European Parliament's Committee on Employment and Social Affairs, Brussels, European Parliament (2010). The Lisbon Strategy 2000-2010: An Analysis and evaluation of the methods used and results achieved, Brussels. Retrieved from: http://www.europarl.europa.eu/document/ activities/cont/201107/20110718ATT24270/20110718ATT24270EN.pdf [accessed: 20.01.2019].

3. Institute for the Future for the University of Pheonix Research Institute (2011). Future Work Skills 2020. Retrieved from: http://www.iftf.org/uploads/media/SR-1382A_UPRI_future_ work_skills_sm.pdf [accessed: 20.01.2019].

\section{Internet based sources:}

1. Cohan, P. (2016). The Four Stages of Start-up Growth (and How to Manage Them). Retrieved from: https://www.inc.com/peter-cohan/the-four-stages-of-startup-growth-and-how-tomanage-them.html [accessed: 20.01.2019].

2. Dibner, G. (2018). There are only three startup stages. Retrieved from: https://medium.com/ angularventures/there-are-only-three-stages-for-startups-b8783d6b0f1 [accessed: 20.01.2019].

3. Enterprise Singapore: SME Portal (2015). Singapore. Retrieved from: https://www.smeportal. $\mathrm{sg} /$ content/smeportal/en/moneymatters/assistance-for-startups/tax-exemption-scheme-for-new-startup-companies.html [accessed: 05.04.2019].

4. Lee, A. (2013). Welcome to the Unicorn Club: Learning from Billion-Dollar Start-ups. Retrieved from: https://techcrunch.com/2013/11/02/welcome-to-the-unicorn-club/?guccounter=1 [accessed: 29.01.2019].

5. Magistretti, B., Hensel, A. (2018). VCs invested the most capital in 2017 since the dotcom era. Retrieved from: https://venturebeat.com/2018/01/08/vcs-invested-the-most-capital-in2017-since-the-dotcom-era/ [accessed: 29.01.2019].

6. Meisler, L., Cannon, C. (2018). U.S. Venture Capital Swells and Spreads. Retrieved from: https:// www.bloomberg.com/graphics/2018-venture-capital-deals/ [accessed: 29.01.2019].

7. Myers, W., Do really 9 out of 10 start-ups fail? Retrieved from: https://www.startupfinancialmodel.com/startuptips/do-9-out-of-10-startups-really-fail [accessed: 29.01.2019].

8. Office of Advocacy (2012). Do economic or industry factors affect business survival?, Retrieved from: https://www.sba.gov/sites/default/files/Business-Survival.pdf [accessed: 20.01.2019].

9. Olsen, D. (2017). A record-setting year: 2017 VC activity in 3 charts. Retrieved from: https:// pitchbook.com/news/articles/a-record-setting-year-2017-vc-activity-in-3-charts [accessed: 20.01.2019]. 
10. Petch, N. (2016). The Five Stages of Your Business Lifecycle: Which Phase Are You In? Retrieved from: https://www.entrepreneur.com/article/271290 [accessed: 20.01.2019].

11. Segal, C. The 6 Stages of a Start-up: Where are You?, Retrieved from: https://www.coxblue. com/the-6-stages-of-a-startup-where-are-you/ [accessed: 20.01.2019].

12. Wiltbank, R. (2012). Angel Investors Do Make Mone, Data Shows 2.5x Returns Overall. Retrieved from: https://techcrunch.com/2012/10/13/angel-investors-make-2-5x-returns-overall/ [accessed: 20.01.2019].

13. Wolfson, R. (2018). Maltese Parliament Passes Laws Set Regulatory Framework For Blockchain, Cryptocurrency and DLT. Retrieved from: https://www.forbes.com/sites/rachelwolfson/2018/07/05/maltese-parliament-passes-laws-that-set-regulatory-framework-for-blockchaincryptocurrency-and-dlt/\#7e65e42f49ed [accessed: 5.04.2019].

14. Zahorsky, D. (2019). The 7 Stages of Starting and Running a Business. Retrieved from: https:// www.thebalancesmb.com/find-your-business-life-cycle-2951237 [accessed: 20.01.2019].

\section{Webinars}

1. Sutton, R.I. (2014). Scaling Up Without Screwing Up, Stanford University. Retrieved from: https://www.youtube.com/watch?v=OnQBnvYdXgI

2. Gross, B. (2015). The single biggest reason why start-ups succeed", TED Talk. Retrieved from: https://www.ted.com/talks/bill_gross_the_single_biggest_reason_why_startups_succeed?language $=\mathrm{pl}$ 